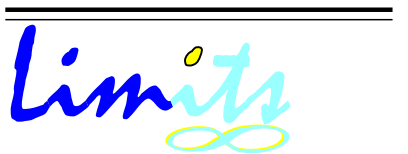

J. Math. and Its Appl.

ISSN : 1829-605X

Vol. 2, No. 2, Nov 2005, 81-92

\title{
Analisis Kestabilan dan Bifurkasi Solusi Sistem Autoparametrik dengan Osilator Tipe Rayleigh
}

\author{
Abadi \\ Jurusan Matematika UNESA \\ Universitas Negeri Surabaya \\ abadi4@yahoo.com
}

\begin{abstract}
Abstrak
Masalah resonansi autoparametrik pada sistem tereksitasi sendiri banyak terjadi pada struktur-struktur mekanika. Paper ini akan menganalisis model rekayasa dari struktur mekanika yang sesungguhnya. Sistem autoparametrik tipe Rayleigh dipelajari untuk melihat perilaku solusinya, kasus-kasus bifurkasi solusi yang mungkin.
\end{abstract}

Keywords. Autoparametrik, tereksitasi sendiri, resonansi, bifurkasi.

\section{Pendahuluan}

Studi tentang resonansi autoparametrik sangat diperlukan, khususnya apabila kita ingin menghindari efek-efek yang tidak diinginkan atau ingin mendapatkan gerakan osilasi dengan frekuensi tertentu dari sistem. Di samping itu, terdapat fenomena matematis yang menarik yang diperoleh dari resonansi autoparametrik, antara lain: solusi periodik, bifurkasi dan chaos. 


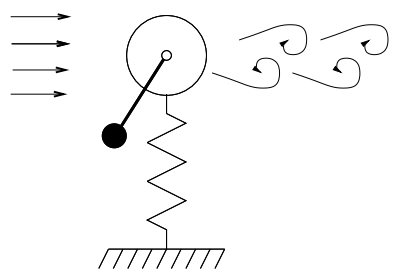

Gambar 1: Model pegas-massa.

\section{Resonansi Autoparametrik}

Sistem autoparametrik adalah sistem bergetar yang terdiri sekurang-kurangnya dua subsistem, yaitu Sistem Utama (osilator) dan Sistem Sekunder (sistem tereksitasi). Sistem Utama dapat bergetar karena gaya luar (externally forced), tereksitasi parametrik (parametrically excited), tereksitasi sendiri (self-excited), atau kombinasi dari ketiganya. Sistem Utama dapat mempunyai $N$ buah derajat kebebasan yang dideskripsikan oleh koordinat-koordinat $x_{i}, \dot{x}_{i}, i=1,2, \ldots, N$. Sistem sekunder dirangkaikan ke Sistem Utama secara tak linier, sedemikian hingga memungkinkan Sistem Sekunder diam, sementara Sistem Utama bergetar. Keadaan ini disebut Solusi Semitrivial atau Modus Normal.

Di dalam selang (parameter) ketakstabilan solusi semitrivial terjadi resonansi autoparametrik atau ketakstabilan autoparametrik. Bergetarnya Sistem Utama menjadi sumber eksitasi parametrik dari Sistem Sekunder, sehingga Sistem Sekunder tidak lagi dalam keadaan diam. Situasi ini disebut eksitasi autoparametrik.

Paper ini membahas sistem autoparametrik tereksitasi sendiri. Sebuah model sederhana dari sistem autoparametrik tereksitasi sendiri adalah sistem pegasmassa pada medium yang mengalir (misal: angin atau arus air). Medium yang mengalir dengan kecepatan tetap menjadi sumber tereksitasinya sistem, seperti dideskripsikan dalam Gambar 1. Ketika aliran mengenai Sistem Utama, solusi semitrivial/modus normal tidak stabil, dan energi perlahan-lahan berpindah ke gerakan berayun dari Sistem Sekunder. Pembahasan lebih lengkap tentang sistem autoparametrik lihat [1].

\section{Metode Averaging dan Analisis Bifurkasi}

Solusi periodik atau sikel limit limit cycle merupakan hal yang khas dari sistem yang memuat osilator tereksitasi sendiri. Kita memandang masalah getaran di paper ini merupakan perturbasi (gangguan) kecil dari suatu masalah yang telah diketahui. Sehingga, kita gunakan metode perturbasi untuk menghitung pendekatan solusi periodik dari sistem. Kita menghitung bentuk normal (normal form) dari 
sistem melalui metode averaging [2].

Pertimbangkan sistem persamaan dalam bentuk standard

$$
\dot{\mathbf{x}}=\varepsilon f(t, \mathbf{x})+\varepsilon^{2} g(t, \mathbf{x}, \varepsilon), \mathbf{x}(0)=\mathbf{x}_{\mathbf{0}},
$$

dengan $\mathbf{x} \in \mathfrak{D} \subset \mathbb{R}^{n}$ dan $\varepsilon$ parameter positif yang cukup kecil nilainya. Diasumsikan bahwa $f(t, \mathbf{x})$ fungsi periodik-T dalam $t$, maka rerata (average) $f$ didefinisikan:

$$
f^{0}(\mathbf{y})=\frac{1}{T} \int_{0}^{T} f(t, \mathbf{y}) d t .
$$

Sekarang kita perhatikan masalah nilai awal

$$
\dot{\mathbf{y}}=\varepsilon f^{0}(\mathbf{y}), \mathbf{y}(0)=\mathbf{x}_{\mathbf{0}} .
$$

Fungsi vektor $\mathbf{y}(t)$ menyatakan sebuah pendekatan dari $\mathbf{x}(t)$ sebagai berikut:

Teorema 3.1 Perhatikan masalah nilai awal (1) dan (2) dengan $\mathbf{x}, \mathbf{y}, \mathbf{x}_{\mathbf{0}} \in$ $\mathbb{R}^{n}, t \geq 0$. Apabila:

a. fungsi-fungsi vektor $f, g$ and $\frac{\partial f}{\partial x}$ terdefinisi, kontinu dan terbatas oleh konstanta $M$ (bebas terhadap $\varepsilon$ dalam $[0, \infty) \times D$;

b. $g$ kontinu Lipschitz dalam $x$ untuk $x \in D$;

c. $f(t, \mathbf{x})$ periodik- $T$ dalam $t$ dengan rerata $f^{0}(\mathbf{x})$; T konstanta yang bebas terhadap $\varepsilon$;

d. $\mathbf{y}(t)$ termuat dalam suatu subset dalam (internal subset) dari $D$.

Maka $\mathbf{x}(t)-\mathbf{y}(t)=\mathcal{O}(\varepsilon)$ pada skala waktu $\frac{1}{\varepsilon}$. (Bukti lihat Sander dan Verhulst [2].)

Kita melakukan linierisasi terhadap sistem terratakan (averaged system) (2) untuk menentukan perilaku pendekatan solusi periodik di sekitar titik tetap (fixed point) dari sistem. Di samping itu, analisis bifurkasi dari solusi tersebut dapat pula dilakukan. Analisis bifurkasi digunakan untuk mengetahui perilaku kualitatif pendekatan solusi periodik dari sistem secara utuh.

Suatu sistem dimensi $n$ dinyatakan dalam:

$$
\dot{\mathbf{x}}=f(t, \mathbf{x}, \mu), \mathbf{x} \in \mathbb{R}^{n}, \mu \in \mathbb{R}^{k},
$$

$\mu$ menyatakan parameter kontrol dari sistem, yang dapat berupa koefisien gesek atau konstanta coupling pada sistem mekanika. Pada kenyataannya kita tidak pernah mengetahui nilai eksak dari $\mu$. Maka hal yang menarik adalah bagaimana perilaku solusi sistem bila nilai parameter diubah-ubah. Sehingga dimungkinkan 
untuk memperoleh nilai kritis $\mu_{c}$ (disebut nilai bifurkasi), di mana sifat/perilaku solusi sistem berubah secara kualitatif. Perubahan sifat/perilaku dari solusi sistem sangat penting dalam aplikasi.

Pada paper ini kita mengevaluasi hasil-hasil perhitungan analitis dengan melakukan analisis numerik. Kita menggunakan paket perangkat lunak CONTENT dan DsTool (lihat Kuznetsov dan Levitin [3]) dan [4], program kontinuasi untuk menganalisis bifurkasi dari solusi periodik secara numerik.

\section{Sistem Autoparametrik dengan Osilator Tipe Rayleigh}

Kita pertimbangkan sistem autoparametrik tereksitasi sendiri tipe Rayleigh dalam bentuk tanpa dimensi (non-dimensional):

$$
\begin{aligned}
x^{\prime \prime}-\beta\left(1-x^{\prime 2}\right) x^{\prime}+x+\gamma_{1} y^{2} & =0 \\
y^{\prime \prime}+\kappa y^{\prime}+q^{2} y+\gamma_{2} x y & =0
\end{aligned}
$$

dengan $\beta>0$, merupakan koefisien eksitasi diri (the self-excitation coefficient), $\kappa>0$ koefisien redaman dari Sistem Sekunder, $\gamma_{1}$ and $\gamma_{2}$ koefisien coupling tak linier; $q$ merupakan koefisien penyelaras (tuning coefficient) yang menyatakan perbandingan antara frekuensi-frekuensi natural dari sub-sub sistem terlinierisasi tak teredam, di mana frekuensi dari modus $x$ ternormalkan ke 1 . Kita membatasi diskusi dengan hanya memperhatikan resonansi penting $q=\frac{1}{2}$ dan nilai-nilai di persekitarannya. Simbol ' menyatakan turunan terhadap peubah waktu tanpa dimensi. Persamaan pertama dari (4) menyatakan gerakan osilator, sedangkan persamaan kedua menyatakan gerakan Sistem Sekunder. Kita memilih suku-suku coupling taklinier yang berperan dalam terjadinya ketakstabilan solusi semitrivial dan resonansi autoparametrik.

Kita mengasumsikan bahwa nilai semua parameter dalam sistem (4) kecil dan untuk mengaplikasikan metode averaging kita lakukan rescaling sebagai berikut. Misal $\beta=\varepsilon \bar{\beta}, \kappa=\varepsilon \bar{\kappa}, \gamma_{1}=\varepsilon \overline{\gamma_{1}}, \gamma_{2}=\varepsilon \overline{\gamma_{2}}$, dan ambil $q^{2}=\frac{1}{4}+\varepsilon \sigma$, dengan $\sigma$ koefisien detuning. Kemudian, substitusi ke Persamaan (4), setelah menghapus garis atas, kita peroleh bentuk standard berikut:

$$
\begin{aligned}
x^{\prime \prime}+x & =\varepsilon\left(\beta\left(1-{x^{\prime}}^{2}\right) x^{\prime}-\gamma_{1} y^{2}\right) \\
y^{\prime \prime}+\frac{1}{4} y & =-\varepsilon\left(\kappa y^{\prime}+\sigma y+\gamma_{2} x y\right) .
\end{aligned}
$$




\section{Solusi Semitrivial dan Kestabilannya}

Solusi semitrivial terdefinisi sebagai solusi sistem (5) dengan mengambil $y=0$. Kita peroleh persamaan Rayleigh

$$
x^{\prime \prime}+x=\varepsilon \beta\left(1-x^{\prime 2}\right) x^{\prime}, y=0 .
$$

Kita gunakan pemisalan $x(\tau)=R \cos (\tau+\psi)$ dengan $x^{\prime}(\tau)=-R \sin (\tau+\psi)$ untuk mendapatkan persamaan diferensial untuk $R$ dan $\psi$; setelah averaging dalam $\tau$, kita peroleh:

$$
\begin{aligned}
R^{\prime} & =\varepsilon \frac{1}{2} \beta R\left(1-\frac{3}{4} R^{2}\right) \\
\psi^{\prime} & =0 .
\end{aligned}
$$

Hanya mempertimbangkan solusi $R$ tak nol, kita peroleh $R=R_{0}=\sqrt{\frac{4}{3}}$. Karena sifat translasi pada sistem autonomus kita dapat mengambil $\psi=\psi_{0}=0$. Jadi $x_{0}(\tau)=R_{0} \cos \left(\tau+\psi_{0}\right)=\sqrt{\frac{4}{3}} \cos \tau$ merupakan pendekatan solusi periodik dari (6) sampai $\mathcal{O}(\varepsilon)$. Dari Persamaan (7) dapat disimpulkan bahwa solusi semitrivial merupakan solusi periodik yang stabil dengan periode mendekati $2 \pi$. (Stabil di persamaan (6)).

Untuk mengetahui kestabilan solusi semitrivial $x_{0}(\tau)$ di sistem keseluruhan (5), kita gunakan perturbasi kecil terhadap solusi semitrivial, yaitu, kita gunakan perturbasi:

$$
x=x_{0}(\tau)+u \text {, and } y=0+v .
$$

Kemudian kita substitusi (8) ke sistem (5). Setelah melakukan linierisasi, kita peroleh persamaan terpisah berikut:

$$
\begin{aligned}
u^{\prime \prime}+u & =\varepsilon \beta\left(1-3 x_{0}^{\prime}(\tau)^{2}\right) u^{\prime}, \\
v^{\prime \prime}+\frac{1}{4} v & =-\varepsilon\left(\kappa v^{\prime}+\sigma v+\gamma_{2} x_{0}(\tau) v\right) .
\end{aligned}
$$

Melakukan metode averaging (dengan mengambil $u(\tau)=r \cos (\tau+\varphi), u^{\prime}(\tau)=$ $-r \sin (\tau+\varphi)$ untuk persamaan pertama pada (9)), dapat disimpulkan bahwa $u=0$ stabil. Jadi, solusi semitrivial stabil dalam arah $x$. Sekarang kita menganalisis persamaan kedua dalam (9) untuk mengetahui kestabilan solusi semitrival dalam sistem keseluruhan.

Persamaan kedua pada Persamaan (9) merupakan persamaan tipe Mathieu dengan domain ketakstabilan utama diperoleh untuk nilai $q$ di dekat $\frac{1}{2}$. (Lihat [5] Appendix 2, untuk deskripsi tentang persamaan Mathieu). Dengan memisalkan

$$
v(\tau)=R \cos \left(\frac{1}{2} \tau+\psi\right), \text { dengan } v^{\prime}(\tau)=-\frac{1}{2} R \sin \left(\frac{1}{2} \tau+\psi\right) .
$$


Kemudian substitusi ke Persamaan (9) untuk $v$, maka setelah averaging terhadap over $\tau$ dengan faktor rescale $\varepsilon$, kita peroleh:

$$
\begin{aligned}
R^{\prime} & =-\frac{1}{4} \kappa R+\frac{1}{4} R \gamma_{2} R_{0} \sin 2 \psi, \\
\psi^{\prime} & =\frac{1}{2} \sigma+\frac{1}{4} \gamma_{2} R_{0} \cos 2 \psi,
\end{aligned}
$$

di mana $R_{0}$ merupakan amplitudo solusi semitrivial.

Dari ruas kanan Persamaan (11), peubah $\psi$ dapat dieliminasi untuk memperoleh relasi untuk batas domain kestabilan:

$$
R_{c}^{2}=R_{0}^{2}=\frac{1}{\gamma_{2}^{2}}\left(\kappa^{2}+4 \sigma^{2}\right)
$$

di mana $R_{c}$ berarti $R$ kritis. Jadi, untuk $q^{2}=\frac{1}{4}+\varepsilon \sigma$, kita mempunyai nilainilai batas kestabilan yang dinyatakan sebagai hubungan antara $q$ dan $\kappa$ sebagai berikut:

$$
q^{2}=\frac{1}{4}+\varepsilon \sqrt{\frac{\gamma_{2}^{2} R_{0}^{2}-\kappa^{2}}{4}}
$$

untuk $\kappa \leq \gamma_{2} \sqrt{\frac{4}{3}}$. Sebagai ilustrasi, kita ambil $\gamma_{2}=2, \kappa=1$, dan kita peroleh kurva batas kestabilan solusi semitrivial seperti ditunjukkan oleh kurva $R_{c}$ pada Gambar 2. Nilai $\kappa=\gamma_{2} \sqrt{\frac{4}{3}}$ adalah nilai bifurkasi di mana solusi semitrivial berubah sifatnya (menjadi takstabil) dan solusi taktrivial muncul. Kita akan mempelajari fenomena ini di subbab berikut.

\section{Analisis Solusi Taktrivial}

Solusi taktrivial dari (5) untuk $\varepsilon=0$ dapat ditulis sebagai berikut:

$$
x=R_{1} \cos \left(\tau+\psi_{1}\right) \text { and } y=R_{2} \cos \left(\frac{1}{2} \tau+\psi_{2}\right) .
$$

Substitusi (14) ke Persamaan (5), kita dapat mengaplikasikan metode averaging, dan memperoleh

$$
\begin{aligned}
R_{1}^{\prime} & =\frac{1}{2} \beta R_{1}-\frac{3}{8} \beta R_{1}^{3}+\frac{1}{4} \gamma_{1} R_{2}^{2} \sin \left(\psi_{1}-2 \psi_{2}\right) \\
\psi_{1}^{\prime} & =\frac{1}{4} \gamma_{1} \frac{R_{2}^{2}}{R_{1}} \cos \left(\psi_{1}-2 \psi_{2}\right) \\
R_{2}^{\prime} & =-\frac{1}{2} \kappa R_{2}-\frac{1}{2} \gamma_{2} R_{1} R_{2} \sin \left(\psi_{1}-2 \psi_{2}\right) \\
\psi_{2}^{\prime} & =\sigma+\frac{1}{2} \gamma_{2} R_{1} \cos \left(\psi_{1}-2 \psi_{2}\right) .
\end{aligned}
$$


Kita perhatikan bahwa kombinasi sudut $\phi=\psi_{1}-2 \psi_{2}$ pada sistem (15) dapat digunakan untuk mengubah sistem menjadi lebih sederhana:

$$
\begin{aligned}
R_{1}^{\prime} & =\frac{1}{2} \beta R_{1}-\frac{3}{8} \beta R_{1}^{3}+\frac{1}{4} \gamma_{1} R_{2}^{2} \sin \phi \\
R_{2}^{\prime} & =-\frac{1}{2} \kappa R_{2}-\frac{1}{2} \gamma_{2} R_{1} R_{2} \sin \phi \\
\phi^{\prime} & =-2 \sigma+\left(\frac{1}{4} \gamma_{1} \frac{R_{2}^{2}}{R_{1}}-\gamma_{2} R_{1}\right) \cos \phi .
\end{aligned}
$$

Untuk menghindari nilai singular pada medan vektor dalam sistem (16) (lihat persamaan untuk $\phi^{\prime}$ ) kita definisikan

$$
\rho=R_{2}^{2}, u=R_{1} \cos \phi, v=R_{1} \sin \phi,
$$

dan diperoleh sistem

$$
\begin{aligned}
\rho^{\prime} & =-\kappa \rho-\gamma_{2} \rho v \\
u^{\prime} & =\frac{1}{2} \beta\left(1-\frac{3}{4} R_{1}^{2}\right) u+\gamma_{2} u v+2 \sigma v \\
v^{\prime} & =\frac{1}{2} \beta\left(1-\frac{3}{4} R_{1}^{2}\right) v+\frac{1}{4} \gamma_{1} \rho-\gamma_{2} u^{2}-2 \sigma u,
\end{aligned}
$$

di mana $R_{1}^{2}=u^{2}+v^{2}$.

Dalam mempelajari sistem kita akan membahas kasus resonansi eksak $(\sigma=0)$. Titik-titik tetap dari (18) berkorespondensi dengan solusi periodik dari sistem (15). Kita akan menentukan titik-titik tetap tersebut. Kemudian dengan menetapkan nilai-nilai parameter $\beta, \gamma_{1}, \gamma_{2}$ dan membiarkan nilai $\kappa$ berubah, kita akan mempelajari bifurkasi dari titik-titik tetap tersebut.

\subsection{Resonansi Eksak}

Dengan mengambil $\sigma=0$ dan mengasumsikan $\beta>0, \gamma_{1}>0$, dan $\gamma_{2}>0$, sistem (18) menjadi

$$
\begin{aligned}
\rho^{\prime} & =-\kappa \rho-\gamma_{2} \rho v \\
u^{\prime} & =\frac{1}{2} \beta\left(1-\frac{3}{4}\left(u^{2}+v^{2}\right)\right) u+\gamma_{2} u v \\
v^{\prime} & =\frac{1}{2} \beta\left(1-\frac{3}{4}\left(u^{2}+v^{2}\right)\right) v+\frac{1}{4} \gamma_{1} \rho-\gamma_{2} u^{2} .
\end{aligned}
$$

Sistem (19) invarian di bawah transformasi $(\rho, u, v) \rightarrow(\rho,-u, v) . \rho=0$ merupakan manifold invarian dari sistem. Karena dengan mengambil $\rho=0$ kita kembali ke analisis sebelumnya tentang solusi semitrivial. Demikian pula $u=0$ merupakan manifold invarian dari sistem(19). Pada manifold ini terdapat simetri yang lebih diakibatkan oleh implementasi transformasi (17). 


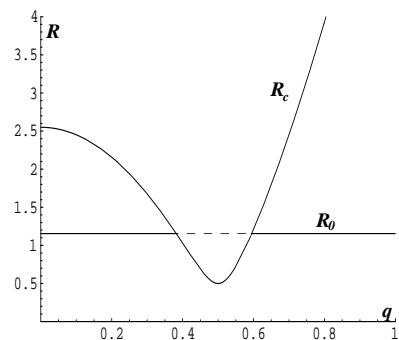

Gambar 2: $R_{0}$ dan $R_{c}$

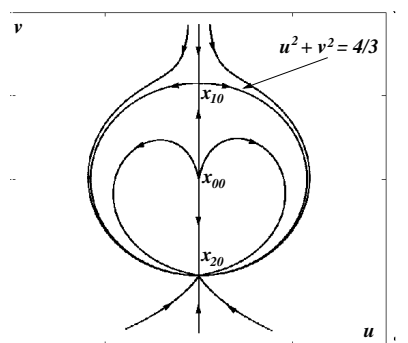

Gambar 3: Dinamik di Bidang $u-v$

\subsubsection{Titik Tetap dan Analisis Bifurkasinya}

Untuk menganalisis titik-titik tetap sistem (19), kita menggunakan keberadaan manifold invarian $\rho=0$ dan $u=0$.

Untuk menentukan titik-titik tetap dari sistem (19) kita selesaikan $f_{1}(\rho, u, v)=$ $0, f_{2}(\rho, u, v)=0, f_{3}(\rho, u, v)=0$, untuk $\rho, u$, dan $v$, di mana $f_{1}, f_{2}, f_{3}$ adalah ruas kanan dari Persamaan (19). Kita memperoleh titik-titik tetap berikut: $\mathbf{x}_{\mathbf{0 0}}=$ $\left(\rho_{0}, u_{0}, v_{0}\right)=(0,0,0) \quad($ solusi trivial $), \mathbf{x}_{\mathbf{1 0}}=\left(0,0, \sqrt{\frac{4}{3}}\right)$, dan $\mathbf{x}_{\mathbf{2 0}}=\left(0,0,-\sqrt{\frac{4}{3}}\right)$ (solusi semitrivial) dan titik-titik tetap berikut berkorespondensi dengan solusi periodik taktrivial

$$
\mathbf{X}_{\mathbf{1}}=\left(\frac{2 \beta \kappa}{\gamma_{1} \gamma_{2}}\left(1-\frac{3}{4} \frac{\kappa^{2}}{\gamma_{2}^{2}}\right), 0,-\frac{\kappa}{\gamma_{2}}\right)
$$

dan

$$
\mathbf{X}_{\mathbf{2}}=\left(\frac{16}{3} \frac{\gamma_{2}}{\gamma_{1}}\left(1-2 \frac{\kappa}{\beta}\right), \pm \sqrt{\frac{4}{3}\left(1-\frac{3}{4} \frac{\kappa^{2}}{\gamma_{2}^{2}}\right)-\frac{8}{3} \frac{\kappa}{\beta}},-\frac{\kappa}{\gamma_{2}}\right) .
$$

Titik-titik $\mathbf{x}_{\mathbf{0 0}}, \mathbf{x}_{\mathbf{1 0}}$, dan $\mathbf{x}_{\mathbf{2 0}}$ pada manifold invarian $\rho=0$, titik-titik $\mathbf{x}_{\mathbf{0 0}}, \mathbf{x}_{\mathbf{1 0}}, \mathbf{x}_{\mathbf{2 0}}$ dan $\mathbf{X}_{\mathbf{1}}$ pada manifold invarian $u=0$. Kita dapat menganalisis titik-titik tersebut dari manifold-manifoldnya, sedangkan $\mathbf{X}_{\mathbf{2}}$ akan dianalisis secara terpisah.

Kita melakukan analisis linier dengan menggunakan matriks Jacobian sistem (19) berikut.

$$
J=\left(\begin{array}{ccc}
-\kappa-\gamma_{2} v & 0 & -\gamma_{2} \rho \\
0 & \frac{1}{2} \beta-\frac{9}{8} \beta u^{2}-\frac{3}{8} \beta v^{2}+\gamma_{2} v & -\frac{3}{4} \beta u v+\gamma_{2} u \\
\frac{1}{4} \gamma_{1} & -\frac{3}{4} \beta u v-2 \gamma_{2} u & \frac{1}{2} \beta-\frac{3}{8} \beta u^{2}-\frac{9}{8} \beta v^{2}
\end{array}\right)
$$

Pada manifold invarian $\rho=0$, matriks Jacobian yang bersesuaian adalah

$$
J_{1}=\left(\begin{array}{cc}
\frac{1}{2} \beta-\frac{9}{8} \beta u^{2}-\frac{3}{8} \beta v^{2}+\gamma_{2} v & -\frac{3}{4} \beta u v+\gamma_{2} u \\
-\frac{3}{4} \beta u v-2 \gamma_{2} u & \frac{1}{2} \beta-\frac{3}{8} \beta u^{2}-\frac{9}{8} \beta v^{2}
\end{array}\right)
$$


Dengan analisis linier diperoleh bahwa $(0,0)$ yang mempunyai nilai eigen $\lambda_{1}=$ $\lambda_{2}=\frac{1}{2} \beta$ merupakan titik simpul takstabil (unstable node). Untuk titik $\left(0, \sqrt{\frac{4}{3}}\right)$ nilai-nilai eigennya adalah $\gamma_{2} \sqrt{\frac{4}{3}}$ and $-\beta$, yang berkorespondensi dengan titik pelana (saddle point) dengan manifold stabilnya pada sumbu $v$. Titik $\left(0,-\sqrt{\frac{4}{3}}\right)$ mempunyai nilai-nilai eigen $-\gamma_{2} \sqrt{\frac{4}{3}}$ and $-\beta$, yang berkorespondensi dengan titik simpul stabil (stable node).

Untuk $\rho=0$ Titik-titik $\left(0, \sqrt{\frac{4}{3}}\right)$ dan $\left(0,-\sqrt{\frac{4}{3}}\right)$ terhubung oleh kurva separatriks $u^{2}+v^{2}=\frac{4}{3}$. Jadi pada bidang $u-v$ terdapat saddle-node connection yang menghubungkan titik simpul $\left(0,-\sqrt{\frac{4}{3}}\right)$ dan titik pelana $\left(0, \sqrt{\frac{4}{3}}\right)$. Untuk ilustrasi tentang dinamik solusi pada bidang $u-v$ lihat Gambar 3 .

Pada manifold invarian $u=0$, diperoleh matriks Jacobian berikut

$$
J_{2}=\left(\begin{array}{cc}
-\kappa-\gamma_{2} v & -\gamma_{2} \rho \\
\frac{1}{4} \gamma_{1} & \frac{1}{2} \beta-\frac{3}{8} \beta u^{2}-\frac{9}{8} \beta v^{2}
\end{array}\right)
$$

Dengan melakukan analisis serupa dengan sebelumnya, kita peroleh bahwa $(0,0)$ mempunyai nilai-nilai eigen $-\kappa$ dan $\frac{1}{2} \beta$, yang berkorespondensi dengan titik pelana dengan manifold takstabil pada sumbu $v$. Titik $\left(0, \sqrt{\frac{4}{3}}\right)$ mempunyai nilai eigen $-\kappa-\gamma_{2} \sqrt{\frac{4}{3}}$ dan $-\beta$, yang berkorespondensi dengan titik simpul stabil. Hal menarik terjadi pada $\left(0,-\sqrt{\frac{4}{3}}\right)$. Nilai-nilai eigennya adalah $-\kappa+\gamma_{2} \sqrt{\frac{4}{3}}$ dan $-\beta$. Substitusi titik tetap $\left(0,-\sqrt{\frac{4}{3}}\right)$ ke $J_{2}$ kita peroleh:

$$
J_{p}=\left(\begin{array}{cc}
-\kappa+\gamma_{2} \sqrt{\frac{4}{3}} & 0 \\
\frac{1}{4} \gamma_{1} & -\beta
\end{array}\right)
$$

Apabila kita perhatikan perubahan nilai dari parameter $\kappa$, kita peroleh bahwa $\kappa=\gamma_{2} \sqrt{\frac{4}{3}}$ merupakan nilai bifurkasi, di mana karakteristik titik tetap tersebut berubah secara kualitatif ketika nilai $\kappa$ melalui nilai kritis tersebut. Jika $\kappa>\gamma_{2} \sqrt{\frac{4}{3}}$ maka titik $\left(0,-\sqrt{\frac{4}{3}}\right)$ adalah titik simpul stabil. Sedangkan jika $\kappa<\gamma_{2} \sqrt{\frac{4}{3}}$ maka $\left(0,-\sqrt{\frac{4}{3}}\right)$ adalah titik pelana. Untuk mengetahui apa yang terjadi pada $\kappa=\gamma_{2} \sqrt{\frac{4}{3}}$ kita gunakan pendekatan center manifold (lihat [6]).

Pendekatan center manifold memberikan persamaan dinamik di manifold tersebut sebagai berikut.

$$
\bar{\rho}^{\prime}=-\bar{\rho}\left(\bar{\kappa}+2 \bar{\rho}+2\left(1+\frac{3}{4} \sqrt{3}\right) \bar{\rho}^{2}\right) \quad \bar{\kappa}^{\prime}=0,
$$


di mana tanda "-" menunjukkan koordinat baru hasil translasi.

Dari persamaan (26) terdapat bifurkasi pitchfork superkritis di sekitar $(0,0)$. Ketika $\bar{\kappa}=0$, titik $(0,0)$ yang berkorespondensi dengan solusi semitrivial $\mathbf{x}_{\mathbf{2}}$ bercabang; solusi semitrivial kehilangan kestabilannya dan solusi taktrivial stabil muncul. Solusi taktrivial yang terjadi berkorespondensi dengan titik $\left(\frac{2 \beta \kappa}{\gamma_{1} \gamma_{2}}(1-\right.$ $\left.\frac{3}{4} \frac{\kappa^{2}}{\gamma_{2}^{2}}\right),-\frac{\kappa}{\gamma_{2}}$ ) (atau $\mathbf{X}_{\mathbf{1}}$ dalam ruang $\rho-u-v$ ).

Kestabilan solusi taktrivial $\mathbf{X}_{\mathbf{1}}$ dilakukan dengan mensubstitusikannya ke matriks Jacobian ke matriks $J_{2}$, kita peroleh

$$
J_{h}=\left(\begin{array}{cc}
0 & -\frac{2 \beta \kappa}{\gamma_{1}}\left(1-\frac{3}{4} \frac{\kappa^{2}}{\gamma_{2}^{2}}\right) \\
\frac{1}{4} \gamma_{1} & \frac{1}{2} \beta\left(1-\frac{9}{4} \frac{\kappa^{2}}{\gamma_{2}^{2}}\right)
\end{array}\right) .
$$

Dari (27) kita tahu bahwa $\kappa=\frac{2}{3} \gamma_{2}$ merupakan nilai bifurkasi lain, karena untuk $\kappa>\frac{2}{3} \gamma_{2}$ titik tetap tersebut merupakan spiral stabil (stable focus), sedangkan untuk $\kappa<\frac{2}{3} \gamma_{2}$ titik tetap tersebut merupakan spiral takstabil. Karena nilai-nilai eigennya imajiner, yang terjadi adalah bifurkasi Hopf pada nilai kritis tersebut.

Untuk menentukan jenis bifurkasi Hopf, kembali kita gunakan pendekatan center manifold dan kita menganalisis dari persamaan hasil translasi di manifold tersebut:

$$
\hat{\rho}^{\prime}=-\frac{2}{3} \sqrt{2} \hat{v}-2 \hat{\rho} \hat{v} \quad \hat{v}^{\prime}=\frac{2}{3} \sqrt{2} \hat{\rho}+\frac{3}{2} \hat{v}^{2}-\frac{3}{4} \hat{v}^{3} .
$$

Kestabilan sikel limit (limit cycle) yang terjadi pada bifurkasi Hopf dapat ditentukan dengan menghitung kuantitas berikut. (Lihat [7] untuk formulasinya).

$$
\begin{aligned}
a= & \frac{1}{16}\left[f_{x x x}+f_{x y y}+g_{x x y}+g_{y y y}\right]+\frac{1}{16 \omega_{0}}\left[f_{x y}\left(f_{x x}+f_{y y}\right)\right. \\
& \left.-g_{x y}\left(g_{x x}+g_{y y}\right)-f_{x x} g_{x x}+f_{y y} g_{y y}\right],
\end{aligned}
$$

di mana $\omega_{0}=\frac{2}{3} \sqrt{2}, f, g$ masing-masing merupakan ruas-ruas kanan dari persamaan untuk $\hat{\rho}^{\prime}, \hat{v}^{\prime}$ dari (28). Dari perhitungan di atas diperoleh $a=-\frac{9}{32}$. Hal ini menunjukkan bahwa kita memperoleh bifurkasi Hopf superkritis (supercritical Hopf bifurcation), di mana sikel limit stabil terjadi ketika solusi periodik berubah kestabilannya.

Kontinuasi nilai $\kappa$ terhadap sikel limit hasil bifurkasi Hopf menyebabkan pecahnya sikel limit tersebut menjadi sebuah sikel heteroklinik (heteroclinic cycle). Hal ini terjadi pada $\kappa \approx 1.243761$. Ilustrasi selengkapnya ditunjukkan pada Gambar

Analisis terhadap titik tetap $\mathbf{X}_{\mathbf{2}}$ terlalu kompleks apabila menggunakan perhitungan analitis. Oleh karena itu melakukan perhitungan secara numerik dengan menggunakan paket software numerik CONTENT. (Lihat [3] untuk rincian tentang paket tersebut). 


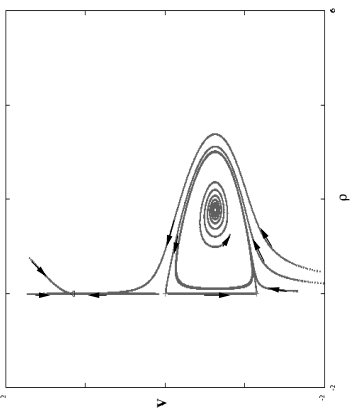

(i)

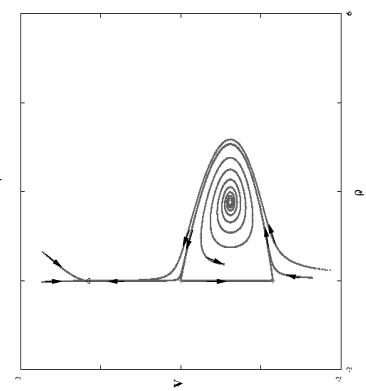

(ii)

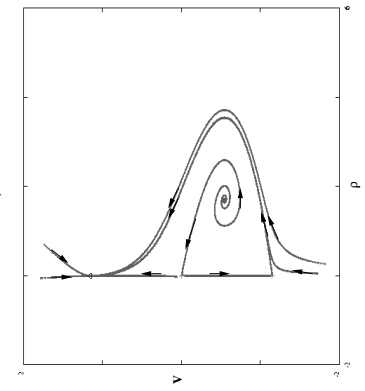

(iii)

Gambar 4: Bifurkasi heteroklinik. Dinamika di bidang $\rho-v$ untuk $\beta=2, \gamma_{1}=$ $1, \gamma_{2}=2$. (i) pada $\kappa=1.26$, (ii) pada $\kappa \approx 1.243761$, (iii) pada $\kappa=1.1$.

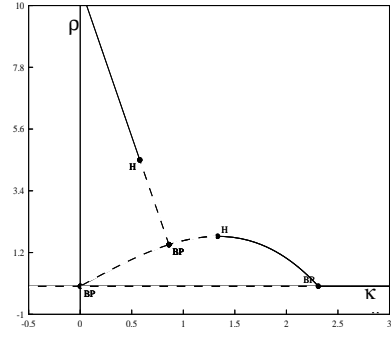

Gambar 5: Resonansi Eksak

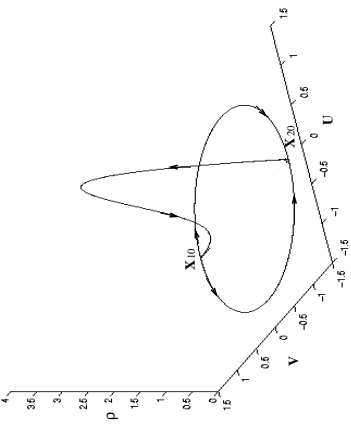

Gambar 6: Sikel heteroklinik robust

Kontinuasi terhadap nilai $\kappa$ dapat dilakukan dengan menggunakan CONTENT untuk memperoleh diagram bifurkasi, $\rho$ sebagai fungsi $\kappa$. Gambar 5 menunjukkan diagram bifurkasi selengkapnya dari sistem.

Pada $\kappa \approx 2.309401$ terjadi bifurkasi pitchfork dari solusi semitrivial, di mana solusi taktrivial stabil $\mathbf{X}_{\mathbf{1}}$ muncul. Sedangkan pada $\kappa \approx 1.333333$ solusi $\mathbf{X}_{\mathbf{1}}$ berubah kestabilan dari spiral stabil menjadi spiral takstabil. Di sini bifurkasi Hopf terjadi; sikel limit stabil terbentuk. Apabila kontinuasi dilanjutkan, akan terdapat percabangan solusi periodik tak stabil pada $\kappa \approx 0.861002$ di mana muncul solusi periodik lain yang berkorespondensi dengan solusi taktrivial $\mathbf{X}_{\mathbf{2}}$. Kemudian pada $\kappa \approx 0.578051$ terjadi bifurkasi Hopf subkritis (subcritical Hopf bifurcation), di mana solusi $\mathbf{X}_{\mathbf{2}}$ berubah kestabilan dari spiral takstabil menjadi spiral stabil dan sikel limit takstabil muncul.

Hal menarik juga terjadi pada sistem (19). Apabila kita integrasi sebuah titik di dekat solusi takstabil pada $\kappa<1.243761$. Solusi tersebut akan konvergen ke 
solusi taktrivial stabil yang berbentuk sikel heteroklinik robust (robust heteroclinic cycle). Hal ini berkaitan dengan saddle-node connection pada bidang $u-v$ dan sikel heteroklinik pada bidang $\rho-v$ seperti ditunjukkan pada Gambar 3 dan Gambar 4. Adapun Gambar 6 mengilustrasikan sikel heteroklinik robust di ruang $\rho-u-v$. Untuk menentukan kestabilan sikel heteroklinik tersebut kita gunakan hasil dari Krupa dan Melbourne [8].

\section{Penutup}

Studi tentang kestabilan dan bifurkasi solusi sistem autoparametrik (4) menunjukkan hasil yang sangat menarik. Kestabilan solusi semitrivial berperan penting dalam rekayasa mekanika. Analisis resonansi eksak menunjukkan bahwa keterbatasan solusi sistem yang ditunjukkan oleh keberadaan sikel heteroklinik robust yang stabil. Analisis lebih lanjut dapat dilakukan untuk kasus resonansi tak eksak $(\sigma \neq 0)$. Studi dapat pula dikembangkan untuk tipe osilator lain (misal: tipe van der Pol), serta mengaplikasikan bentuk coupling yang lebih umum.

\section{Pustaka}

[1] A. Tondl, T. Ruijgrok, F. Verhulst, and R. Nabergoj. Autoparametric Resonance in Mechanical Systems. Cambridge University Press, New York, 2000.

[2] J. A. Sanders and F. Verhulst. Averaging Methods in Nonlinear Dynamical Systems. Appl. Math. Sciences 59, Springer-Verlag, New York, 1985.

[3] Yu A. Kuznetsov and V. Levitin. CONTENT: Integrated Environment for the Analysis of Dymanical Systems, 1997. ftp://ftp.cwi.nl/pub/CONTENT.

[4] J. Guckenheimer, M. R. Myers, F. J. Wicklin, and P. A. Worfolk. DsTool: Dynamical Sys Toolkits with an Int. Graph. Interface, User's Manual, 1995.

[5] F. Verhulst. Nonlinear Differential Equations and Dynamical Systems. Springer-Verlag, Berlin, 2000.

[6] J. Carr. Applications of Centre Manifold Theory. Appl.Math.Sciences 35, Springer-Verlag, New York, 1981.

[7] J. Guckenheimer and P. Holmes. Nonlinear Oscillations, Dynamical Systems, and Bifurcations of Vector Fields. Appl.Math.Sciences 42, Springer-Verlag, New York, 1997.

[8] M. Krupa and I. Melbourne. Asymptotic Stability of Heteroclinic Cycles in Systems with Symmetry. Ergod. Th. \& D Dynam. Sys., 15:121-147, 1995. 